\title{
The Development Law of the Freezing Temperature Field of a Calcareous Clay Layer
}

\author{
Zhi Wang, ${ }^{1}$ Chuanxin Rong $\mathbb{D}^{1},{ }^{1}$ Meng Du, ${ }^{1}$ Maoyan $\mathrm{Ma}^{2}{ }^{2}$ and Xiangyang Liu $\mathbb{D}^{1,2}$ \\ ${ }^{1}$ College of Civil Engineering and Architecture, Anhui University of Science and Technology, Huainan 232001, China \\ ${ }^{2}$ Anhui Province Key Laboratory of Building Structure and Underground Engineering, Hefei 230601, Anhui, China \\ Correspondence should be addressed to Chuanxin Rong; rongcx@ustc.edu
}

Received 30 July 2020; Accepted 17 September 2020; Published 24 October 2020

Academic Editor: Shaohui Wang

Copyright (c) 2020 Zhi Wang et al. This is an open access article distributed under the Creative Commons Attribution License, which permits unrestricted use, distribution, and reproduction in any medium, provided the original work is properly cited.

The problem of "difficult" freezing of the calcareous clay layer fractures in freezing pipes has been investigated. Based on the engineering background of the deep calcareous clay in the Yangcun Mine, model tests were carried out in order to conduct indepth research on the development law of the freezing temperature field of this clay layer. The test results have shown that the calcareous clay has a freezing point of $-1.3^{\circ} \mathrm{C}$ under the action of both the water and the soil's chemistry and the supercooling temperature can be as low as $-3.8^{\circ} \mathrm{C}$ because of its complex mineral composition causing poor thermal conductivity. This means that the calcareous clay will freeze slowly than the other layers of the soil. The time taking for the temperature fields to intersect is $2.5 \mathrm{~h}$, which is equivalent to 127.6 days in the actual engineering. In the three sections, each temperature measurement point in the temperature field had an irregular saddle shape in the temperature space at the same time, and the ratio of the time between the formation and total melting of the frozen wall was $1: 1.91$. The development speed of the thickness of the frozen wall from $5 \mathrm{~h}$ to $16 \mathrm{~h}$ was $17.9 \mathrm{~mm} / \mathrm{h}$, and the development speed from $16 \mathrm{~h}$ to $70 \mathrm{~h}$ was $1.96 \mathrm{~mm} / \mathrm{h}$; corresponding to the actual development speed of the thickness of the frozen wall which were $0.0123 \mathrm{~m} / \mathrm{d}$ and $0.0014 \mathrm{~m} / \mathrm{d}$, respectively. These speeds were significantly slower than the development speed of the thickness of the freezing wall of the general sandy clay layer, which were $0.0515 \mathrm{~m} / \mathrm{d}$ in the early stage and $0.02 \mathrm{~m} / \mathrm{d}$ in the later stage. The thin thickness and low strength of the frozen wall of the calcareous clay layer cause the fracture of the frozen pipes, which should be paid attention to in actual engineering construction.

\section{Introduction}

The artificial ground freezing method entails burying a predetermined number of freezing pipes in order to realize heat exchange with the rock and soil through the circulation of a refrigerant. This is done to form a freezing curtain with a certain strength and a water-tight seal, thus creating good "dry ground" construction conditions for underground geotechnical engineering. As an important temporary support structure in the construction of underground frozen rock and soil, the freezing wall technique has unique "natural" advantages, and it also involves many scientific problems: the freezing of the water in the soil which produces frost heave and the formation law of the freezing temperature field, as well as the strength and thickness of the frozen wall, the difficulty of freezing soil with different properties, the influence of the flow velocity and salinity on the formation of the frozen wall, the influence of frost heave and thaw settlement of the ground on the surrounding structures $[1,2]$, etc. The freezing temperature field is formed. The study of laws is the most basic. Zhang et al. [3-5], Xiangdong et al. [6-8], and Chuanxin et al. [9-11] idealized the temperature field into a trapezoid or parabola, based on the macroscopic characteristics of the freezing temperature field of multiple rows of tubes, a detailed theoretical analysis of the force state of the frozen wall. However, factors such as the difference in the stratum, the response of soil with different properties at low temperatures, the water content, and the latent heat of the phase change [12] make the process of forming the temperature field both changeable and complicated. In view of the difference in freezing process of different soil layers, He [13] considered the effect of different thicknesses of the sand layer on the temperature of the permafrost and carried out indoor experiments to study the degree of its influence. Haipeng [14] 
studied clay using the double coiled tube model test and the frost heave force that was generated during the formation of the frozen wall. The results showed that the frost heave force was closely related to the temperature and that it manifested as spatiotemporal inhomogeneity. Wang and Zhou [15] considered the spatial variability of the soil parameters and combined thermal conductivity and the volumetric heat simulation in a random field, and the research showed that this method was more scientific and suitable. Jinhua [16] carried out model tests to investigate the deformation law of a frozen pipe under the condition of multiloop pipe freezing; they found that the frozen pipe was broken during the excavation stage. The deformation had been basically completed in the early stage of the freezing, and the amount of strain in the frozen pipe in the clay layer was greater than that in the sand layer; this has provided a basis for reducing excavation in the later period and therefore reducing the rate of damage to frozen pipes.

The depth of excavation shafts in coal mines keeps increasing year on year, and deep and water-rich loose alluvial strata have been encountered in many areas in China during the process of freezing shaft sinking. In the Lianghuai mining area, Shungeng Mountain is the boundary to the northwest and the thickness of the alluvial layer gradually deepens. This loose layer is mainly composed of clay, calcareous clay, silty clay, sand, and gravel layers. Freezing pipe fractures often occur when sinking freezing pipes in this soil layer. Distresses often occur, such as when the Pan Sandong air shaft was excavated in an expansive calcareous clay layer with a depth of $252.0 \sim 326.0 \mathrm{~m}, 22$ pipes were broken in the process. 34 pipes were broken in a clay layer with a depth of $224.4 \sim 237.1 \mathrm{~m}$ during the construction of the Xieqiao gangue well [17-19]. When the auxiliary shaft of the Yangcun Mine was excavated to a depth of $404.0 \sim 412.0 \mathrm{~m}$, fractures occurred in 15 freezing pipes. The statistics have shown that fractures of freezing pipes generally occurred at the junction of the calcareous clay layer and the sand layer. According to numerous inspections of the mine's site and related studies [20,21], it was found that it is difficult to form an "effective" frozen wall in this layer of calcareous clay compared to other strata. Therefore, it is necessary to conduct in-depth research on the "hard" freezing characteristics of calcareous clay. In this paper, the deep calcareous clay layer (at a depth of $407.3 \sim 445.3 \mathrm{~m}$ ) of the Yangcun Mine has been taken as the research object. Through indoor model tests and quantitative analysis of the expansion of the calcareous clay, the freezing temperature field and the development law of the frozen wall have been ascertained; these can therefore be used to provide a reference for engineering practice.

\section{Mineral Composition and Thermal Conductivity of Calcareous Clay}

Figure 1 shows the measured temperature curve for hole No. 2 during the artificial freezing process of the auxiliary shaft of the Yangcun Mine. From the figure, it can be seen that the measured temperature of the calcareous clay layer was both higher and lower than the two layers under the same freezing conditions (the clay layer and the fine sand layer). The temperature of the calcareous clay layer was $6 \sim 8$ higher, thus showing its "difficult" freezing characteristics.

The reason for the "difficult" freezing of calcareous clay is mainly due to its complex mineral composition, as shown in Table 1 (X-ray diffraction test ( XRD) results of dried soil samples), containing $\mathrm{Fe}, \mathrm{Mn}, \mathrm{Ti}, \mathrm{Ca}, \mathrm{K}, \mathrm{S}, \mathrm{P}, \mathrm{Si}, \mathrm{Al}, \mathrm{Na}, \mathrm{Mg}$, and other elements, the corresponding minerals are quartz, kaolinite, muscovite, illite, etc., which belong to calcareous kaolinite-illite mudstone, in which $\mathrm{Al}$ and $\mathrm{Si}$ elements are the main clay minerals and cement chemical composition, of which there is a high content, followed by $\mathrm{Fe}^{3+}, \mathrm{Ca}^{2+}$, and $\mathrm{Mg}^{2+}$, which are ion exchange products; this makes the $\mathrm{Na}^{+}$ content low. The calcareous clay in the original environment is in a water-soil system, and a series of geochemical reactions will occur, mainly including ion exchange, dissolution, and precipitation; the reaction process is jointly controlled by the $\mathrm{pH}$ and the $\mathrm{Ca}^{2+}[22]$ ions in the soil. The exchange of $\mathrm{Na}^{+}$and $\mathrm{K}^{+}$ions on the surface of the colloidal particles of the soil and the high-valency $\mathrm{Ca}^{2+}, \mathrm{Mg}^{2+}$, and $\mathrm{Fe}^{3+}$ ions in the aqueous solution increase the surface charge of the soil, and the specific surface area of the calcareous clay is large (the specific surface area of the calcareous clay can be obtained by the $\mathrm{N}_{2}$ adsorption method $S_{a}=74.07 \mathrm{~m}^{2} / \mathrm{g}$ ), and its adsorption strength is large. The water film on the surface of the particles becomes thicker, and their binding energy is high, so it is difficult to freeze them. Combined with the thickening of the water film and the presence of salt ions, the thermal conductivity of calcareous clay is affected for the following reasons: its freezing temperature is low (Figure 2); the freezing point of calcareous clay is $-1.3^{\circ} \mathrm{C}$; and its supercooling temperature is as low as -3.8 . The presence of salt ions turns the frozen water between the soil particles into a salt solution; this lowers the freezing point of the clay and increases the adsorption strength of the water. If it is to be frozen, a lower temperature is required to overcome the adsorption potential energy; The second is that the thermal conductivity is $40 \%$ and $35 \%$ lower than that of sandy soil and sandy clay at room temperature, while the difference is $46 \%$ and $35 \%$ under freezing conditions, as shown in Table 2. The specific surface area of the particles is large, and the thickness of the combined water film means that most of the calcareous clay particles are not in direct contact with each other. The heat transfer path is the soil particles, water, and soil particles, and the thermal conductivity of water is less than that of the solid particles [23]; therefore, the thermal conductivity of calcareous clay is small. As a result, under the same cooling conditions, a clay layer has poor thermal conductivity, the frozen soil develops slowly, its strength is low, the strength of the frozen wall is uneven in the vertical direction, and shear failure is prone to occur at the interface of adjacent soil layers.

\section{Experimental Design}

\subsection{Basic Assumptions}

(1) The experiment only considered the distribution law of the temperature field in the soil during the freezing process and did not analyze its mechanical 


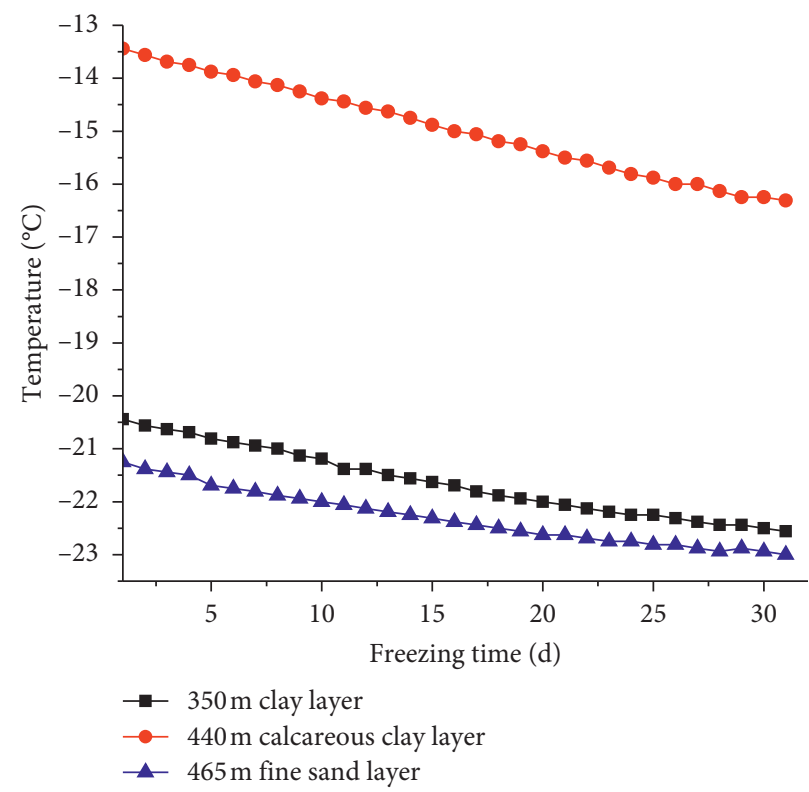

FIGURE 1: Curve of the freezing temperature and the time of the measured temperature of No.2 well in the Yangcun Mine.

TABLE 1: Mineral content of calcareous clay (unit: \%).

\begin{tabular}{lccccccccccc}
\hline Sample & $\mathrm{Fe}_{2} \mathrm{O}_{3}$ & $\mathrm{MnO}$ & $\mathrm{TiO}_{2}$ & $\mathrm{CaO}$ & $\mathrm{K}_{2} \mathrm{O}$ & $\mathrm{SO}_{3}$ & $\mathrm{P}_{2} \mathrm{O}_{5}$ & $\mathrm{SiO}_{2}$ & $\mathrm{Al}_{2} \mathrm{O}_{3}$ & $\mathrm{Na}_{2} \mathrm{O}$ & $\mathrm{MgO}$ \\
\hline Undisturbed soil & 7.69 & 0.063 & 0.76 & 3.72 & 2.02 & 0.10 & 0.085 & 55.32 & 18.91 & 0.25 & 2.87 \\
\hline
\end{tabular}

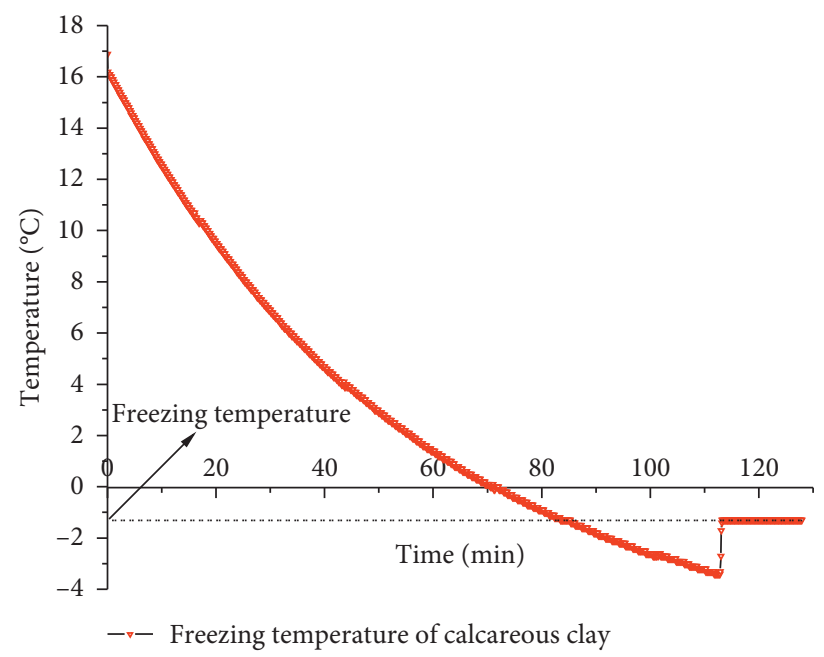

FIGURE 2: Yangcun calcareous clay freezing point experiment.

TABLE 2: Thermodynamic properties of Yangcun frozen soil.

\begin{tabular}{lcccc}
\hline Serial number & Sampling depth $(\mathrm{m})$ & Lithology & \multicolumn{2}{c}{ Thermal conductivity W/(m·K) } \\
& & & Unfrozen soil & Frozen soil \\
\hline 1 & $406-420$ & Calcareous clay & 0.9304 & 1.2705 \\
2 & 260 & Fine sand & 1.55 & 1.85 \\
3 & 1 & Sandy clay & 1.428 & 1.952 \\
\hline
\end{tabular}


characteristics. At the same time, the thermal conductivity of the soil was not correlated with the stress.

(2) The soil was considered to be a continuous medium.

(3) The initial temperature of the soil was assumed to be an equivalent constant (the first type of boundary conditions), and the length of the frozen pipe was kept constant.

3.2. Similarity Criterion for the Experiment. According to the actual working conditions on-site in the Yangcun mine and the existing test conditions in the laboratory, the diameter of the frozen tube that was used in the test was a $6 \mathrm{~mm}$ diameter copper tube in order to ensure the geometric similarity constant of the test, and the design of the test system was carried out accordingly. The size of the box that was used in the experiment was $H=1.2 \mathrm{~m}$ with a diameter $D=1.6 \mathrm{~m}$. The material used in the test was an undisturbed soil sample from the Yangcun site. The term $\pi$ and the similarity criterion equation [24] have been listed according to the dimensions. From the similarity criterion, the time similarity ratio was $C_{\tau}=C_{l}^{2}$ (that is, the time similarity ratio is the square of the geometric similarity ratio), and the temperature similarity ratio was $C_{\theta}=1$ (that is, the temperature at the corresponding points of the model and the prototype was equal), the thermal conductivity similarity ratio was $C_{\alpha_{n}}=1$, and the thermal conductivity similarity ratio was $C_{\lambda_{n}}=1$. Since the test model and the prototype used the same number of frozen tubes, the similarity ratio of the frozen tubes' heat dissipation coefficient and the similarity ratio of the number of frozen tubes in the frozen section were all 1 , that is, $C_{q}=C_{N}=1$. The similarity ratio of the outer diameter of the freezing tubes and the similarity of the freezing depth were $C_{D}=C_{H}=1$ such that the heat flow $C_{Q}=C_{l}^{2}$ was similar to the refrigerant flow rate $v^{\prime}=C_{l} . v$ (that is, the flow rate of the refrigerant in the test was $C_{l}$, which was higher than the actual flow rate of the project). The parameters of the layout and the filling parameters of the freezing pipes have been shown in Table 3 and Figure 3, respectively.

3.3. Layout of the Measuring Points. The temperature measuring points were arranged in two levels: the main level and the auxiliary level. Each level was arranged at three faces, which were the main face, the common interface, and the boundary's main face; there were 6 measuring points on the main surface of the boundary. The arrangement of the specific measuring points and the distance between each measuring point have been shown in Figure 4.

3.4. Test Procedure. The temperature of the test environment was $13^{\circ} \mathrm{C}$, and the box was filled with the original calcareous clay from the Yangcun Mine. The clay was reshaped and filled according to the properties of the original soil. The density of the fill was $\rho=2070 \mathrm{~kg} / \mathrm{m}^{3}$, the moisture content was $25 \%$, and the height of the fill was $h=0.9 \mathrm{~m}$. A $0.3 \mathrm{~m}$ calcareous clay cushion was placed on the bottom of an iron bucket, and then temperature measuring points were located at intervals of $0.3 \mathrm{~m}$, with a total of upper and lower layers. In order to prevent the temperature measurement line from twisting and deflecting during the filling process, a wooden stick was used to accurately position the temperature measurement points. The test's freezing system used an alcohol tank and a freezing control cabinet. The temperature measurement system that was used consisted of a temperature sensor and a data collector. The test process was divided into the freezing process and the thawing process. The freezing pipes were arranged as shown in Figure 5; the model of the freezing test has been shown in Figure 6.

\section{Test Results and Analysis}

\subsection{Time Effect of the Freezing Temperature Field.} Figures $7(a)-7(\mathrm{c})$ show the temperature drop at each temperature measurement point on the upper temperature measuring surface at the common principal surface, the common interface, and the principal boundary surface, respectively. As the temperature drop on the upper and lower temperature measurement surfaces was the same, the upper temperature measurement surface was selected for analysis.

The following can be observed from Figure 7(a): (1) The freezing section and the measuring points A3 and A4 on the common main surface (as shown in Figure 4) were located between the inner and middle rows, and the middle and outer rows, respectively. Close to the freezing tube, as the freezing progressed, the cooling capacity was superimposed to supply, and the temperature decreased the fastest; in the positive temperature zone, the temperature drop is basically linear and rapid. In the negative temperature zone, as the free water in the soil gradually freezes, latent heat is released, and the temperature drop rate is reduced; this process released latent heat, and the average temperature drop rate in the first 16 hours was $2.66^{\circ} \mathrm{C} / \mathrm{h}$ and $2.61^{\circ} \mathrm{C} / \mathrm{h}$, respectively. The freezing process of the rock and the soil was accompanied by various thermophysical and chemical reactions and migration of both water and salt. In the stable freezing period, for the unfrozen water, the increase in the salt concentration meant it was extremely difficult to freeze the strong and weakly bound water. In addition, the temperature difference between the soil and the refrigerant decreased; as a result, the potential energy of the heat exchange decreased, and the rate at which the temperature decreased significantly slowed down. After $60 \mathrm{~h}$, the lowest temperature had reached $-26.1^{\circ} \mathrm{C}$ and $-23.2^{\circ} \mathrm{C}$, respectively; because the cold transfer path of $\mathrm{A} 1$ and $\mathrm{A} 2$ was farther than $\mathrm{A} 3$ and $\mathrm{A} 4$, the rate at which temperature decreased was slow, $0.79^{\circ} \mathrm{C} / \mathrm{h}$ and $1.28^{\circ} \mathrm{C} /$ $\mathrm{h}$, respectively. At the same time, with the continuous supply of cooling capacity, the minimum temperatures of the $\mathrm{A} 1$ and $\mathrm{A} 2$ measuring points reached $-21.5^{\circ} \mathrm{C}$ and $-22^{\circ} \mathrm{C}$, respectively. The measuring point $\mathrm{A} 5$ and the measuring point A2 were the symmetrical measuring points of the outer and inner rows of the three rows of tubes, and these were close to the outer and inner rows of tubes, respectively. During the freezing period of the positive temperature zone, the curves of the temperature reduction of the two were basically the same. But entering the negative temperature zone, the 
TABLE 3: Yangcun coal mining model and the prototype's geometric parameters (ratio of similitude was 35).

\begin{tabular}{|c|c|c|c|}
\hline \multicolumn{2}{|c|}{ Parameter } & \multirow{2}{*}{$\begin{array}{c}\text { Prototype } \\
29.7\end{array}$} & \multirow{2}{*}{$\begin{array}{c}\text { Model } \\
0.848\end{array}$} \\
\hline & Circle diameter $(\mathrm{m})$ & & \\
\hline \multirow[t]{3}{*}{ Outer holes } & Number of holes $(\mathrm{Pc})$ & 55 & 32 \\
\hline & Hole spacing $(\mathrm{m})$ & 1.696 & 0.086 \\
\hline & Circle diameter $(\mathrm{m})$ & 23.3 & 0.666 \\
\hline \multirow[t]{3}{*}{ Middle row of holes } & Number of holes $(\mathrm{Pc})$ & $26 / 26$ & 30 \\
\hline & Hole spacing $(\mathrm{m})$ & 1.407 & 0.072 \\
\hline & Circle diameter $(\mathrm{m})$ & 18.3 & 0.523 \\
\hline \multirow[t]{2}{*}{ Inner row of holes } & Number of holes $(\mathrm{Pc})$ & 26 & 16 \\
\hline & Hole spacing $(\mathrm{m})$ & 2.206 & 0.11 \\
\hline \multicolumn{2}{|c|}{ Frozen wall thickness $(\mathrm{m})$} & 10.7 & 0.306 \\
\hline \multicolumn{2}{|c|}{ Alcohol temperature $\left({ }^{\circ} \mathrm{C}\right)$} & -32 & -32 \\
\hline \multicolumn{2}{|c|}{ Freezing tube's outer diameter (mm) } & 159 & 6 \\
\hline \multicolumn{2}{|c|}{ Freezing wall's average temperature $\left({ }^{\circ} \mathrm{C}\right)$} & -18 & -18 \\
\hline
\end{tabular}

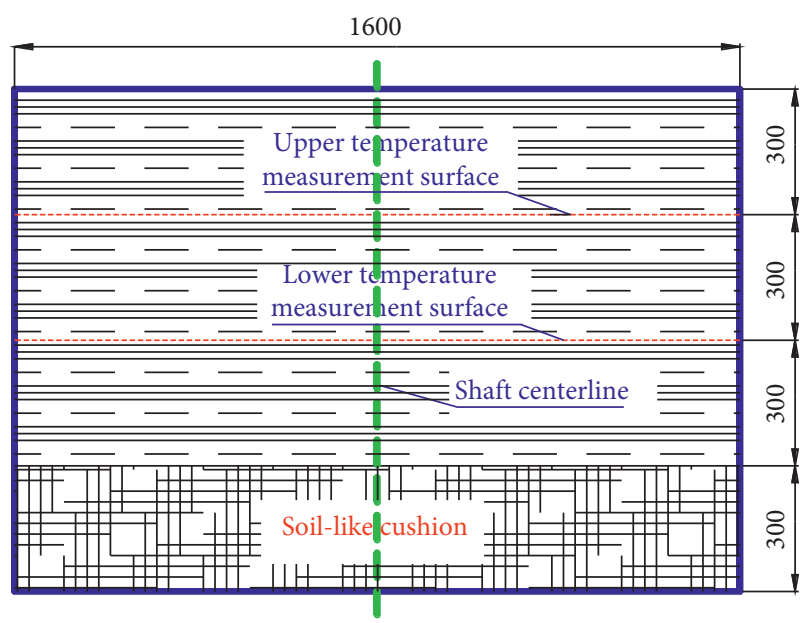

Figure 3: The model's fill map (label length unit: $\mathrm{mm}$ ).

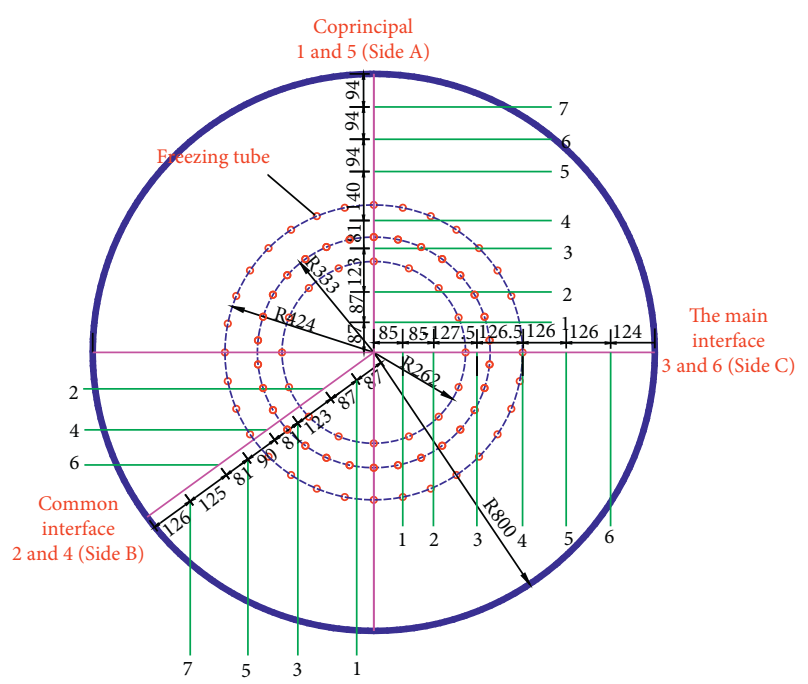

FIGURE 4: Horizontal distribution of the temperature measurement points (label length unit: $\mathrm{mm}$ ).

temperature drop rate of $\mathrm{A} 2$ measuring point is much greater than that of A5 measuring point. The A5, A6, and A7 measuring points had a heat supply for longer time due to the continuous heat supply, which lasted for $72 \mathrm{~h}$; their minimum temperatures were $-8.7^{\circ} \mathrm{C},-1.7^{\circ} \mathrm{C}$, and $3.3^{\circ} \mathrm{C}$, respectively. The temperature reductions rates of points $\mathrm{A} 5$, A6, and A7 were $0.61^{\circ} \mathrm{C} / \mathrm{h}, 0.28^{\circ} \mathrm{C} / \mathrm{h}$, and $0.20^{\circ} \mathrm{C} / \mathrm{h}$, respectively; compared with points $\mathrm{A} 1 \sim \mathrm{A} 4$, the temperature was higher and the temperature reduction was slow, as shown in Table 4 . The minimum temperature at each measuring point (B1 B7) for the common interface shown in Figure 7(b) was $-25.8^{\circ} \mathrm{C},-28.1^{\circ} \mathrm{C},-30.9^{\circ} \mathrm{C},-27.0^{\circ} \mathrm{C},-16.5^{\circ} \mathrm{C},-6.4^{\circ} \mathrm{C}$, and $2.8^{\circ} \mathrm{C}$, respectively, and the temperature reduction rate was $0.79^{\circ} \mathrm{C} / \mathrm{h}, 0.90^{\circ} \mathrm{C} / \mathrm{h}, 1.86^{\circ} \mathrm{C} / \mathrm{h}, 2.41^{\circ} \mathrm{C} / \mathrm{h}, 0.67^{\circ} \mathrm{C} / \mathrm{h}, 0.30^{\circ} \mathrm{C} / \mathrm{h}$, and $0.21^{\circ} \mathrm{C} / \mathrm{h}$, respectively. Figure $7(\mathrm{c})$ shows the measurement points on the main surface $(\mathrm{C} 1 \sim \mathrm{C} 6)$; their minimum temperature was $-25.8^{\circ} \mathrm{C},-27.7^{\circ} \mathrm{C},-29.9^{\circ} \mathrm{C},-21.2^{\circ} \mathrm{C},-6.5^{\circ} \mathrm{C}$, and $1.0^{\circ} \mathrm{C}$, respectively, and their temperature reduction rates were $0.80^{\circ} \mathrm{C} / \mathrm{h}, 0.88^{\circ} \mathrm{C} / \mathrm{h}, 1.37^{\circ} \mathrm{C} / \mathrm{h}, 1.75^{\circ} \mathrm{C} / \mathrm{h}, 0.30^{\circ} \mathrm{C} / \mathrm{h}$, and $0.19^{\circ} \mathrm{C} / \mathrm{h}$, respectively. From the above analysis, it can be seen that the development trends of the freezing temperature field of the three sections were roughly the same. The temperature drop of the common main surface in the area of the freezing wall (measurement points 3 and 4 in each section) was the fastest, and the temperature drop of the common interface was the second fastest. The temperature reduction rate of the No. 1 and No. 2 measuring points for the three cross sections was basically the same, indicating that the freezing wall intersected the area of the three rows of tubes, and the freezing circular front faced the center of the well's bore; there was also stable convective heat transfer in the direction of the line. (2) The reheating section: the hysteresis characteristic of the melting process of the frozen soil [25-28]. In the reheating section, a slow reheating period of nearly $135 \mathrm{~h}$ could be seen, while the freezing section of the curve was due to the long time interval of the test. The cooling rate was too fast to show an obvious phase change or supercooling phenomena in the figure. The water in the soil at the three cross sections $\mathrm{A} 1 \sim \mathrm{A} 4, \mathrm{~B} 1 \sim \mathrm{B} 4$, and $\mathrm{C} 1 \sim \mathrm{C} 4$ melted from the solid phase (ice) turning into the liquid phase (water). The surrounding soil absorbed a lot of heat, and the soil at measuring points 6 and 7 showed no freezing or obvious freezing phenomenon, and the two measuring points of the three sections showed no slow temperature phase change recovery period. 


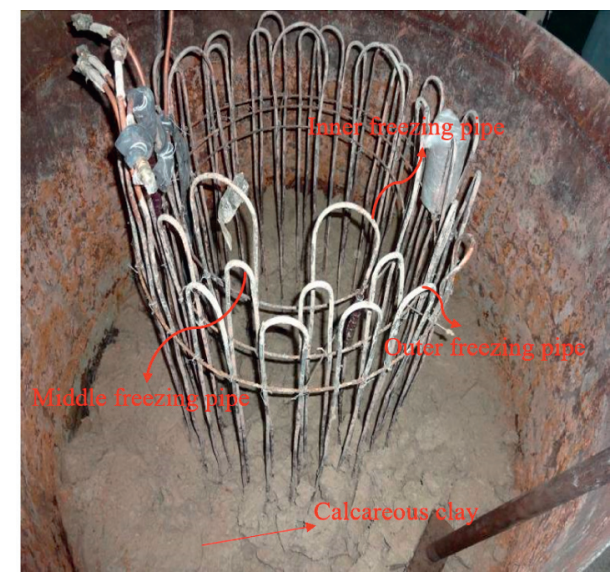

FIgURE 5: Arrangement of the freezing pipes in the experiment.

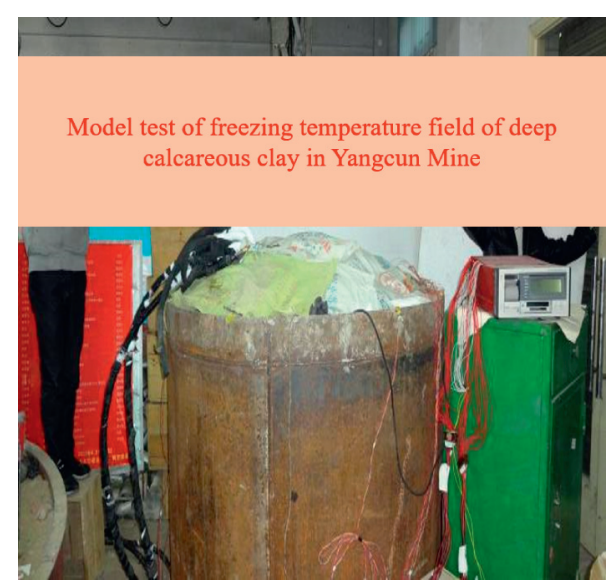

FIgURE 6: The model of the freezing experiment.

4.2. Spatial Effect of the Freezing Temperature Field. During the test, the spatial distribution of the temperature at the freezing point and the return temperature section of each temperature measuring point on the common principal surface, the common interface, and the principal boundary surface at the specified times have been shown in Figure 8.

Figures $8(a)-8(c)$ show the spatial distribution of the freezing temperature of the three cross sections of the freezing section at each temperature measurement point for a certain time interval. It can be seen from the figure that the distributions of the temperature values of the measuring points for the three cross sections were an irregular saddle shape. Taking the coprinciple as an example, the temperature drops at the measuring points A3 and A4 are basically synchronized within 16 hours before the freezing period. At the same time, the temperature difference between the two points is within $0.9^{\circ} \mathrm{C}$, while the maximum temperature difference between points $\mathrm{A} 3$ and $\mathrm{A} 4$ between $16 \mathrm{~h}$ and $64 \mathrm{~h}$ was $3^{\circ} \mathrm{C}$; this was due to the continuous supply of heat from the original ground temperature; therefore, the outer row of pipes needs to provide more cooling to ensure that the outer edge of the frozen wall expands outward.

In the initial stage of the freezing (between 0 to $2 \mathrm{~h}$ ), the temperature changes of the $\mathrm{A} 1$ and $\mathrm{A} 2$ measuring points located in the excavation wasteland and the A5-A7 measuring points located outside the outer row of pipes were not obvious; this was because, in theory, the formation of a frozen front occurred first. On the "circle" locus of the row of pipes, when the temperature of the area reached a certain value, a sufficient temperature potential could form with the adjacent soil body in order to drive the cooling capacity to move inwards and outwards; the number of inner pipes was small, and the distance between the holes was large. At certain times in the positive temperature zone, the temperature of the outside measurement point 5 was lower than those of measurement points 1 and 2 that were located in the excavation barren path (Figures $8(\mathrm{a})$ and $8(\mathrm{~b})$ ). During the entire freezing period, the temperature difference between the A2 and A3, A4 and A5 measuring points was the most obvious. The temperature gradients between the A2 and $\mathrm{A} 3, \mathrm{~A} 4$ and $\mathrm{A} 5$ measuring points were $0.14^{\circ} \mathrm{C} / \mathrm{mm}$ and $0.11^{\circ} \mathrm{C} / \mathrm{mm}$ at $2 \mathrm{~h}$; at both $8 \mathrm{~h}$ and $16 \mathrm{~h}$, the values were $0.17^{\circ} \mathrm{C} / \mathrm{mm}$ and $0.15^{\circ} \mathrm{C} / \mathrm{mm}$, respectively. This indicates that there was stable cooling transfer between the points $\mathrm{A} 2$ and $\mathrm{A} 3$, and A4 and A5 within 2 to 16 hours, and the temperature difference between the A2 and A3, A4 and A5 measurement points during the subsequent freezing period gradually decreased. For example, the gradient between points $\mathrm{A} 2$ and $\mathrm{A} 3$ was $0.097^{\circ} \mathrm{C} / \mathrm{mm}$ at $32 \mathrm{~h}, 0.047^{\circ} \mathrm{C} / \mathrm{mm}$ at $48 \mathrm{~h}$, and $0.018^{\circ} \mathrm{C} / \mathrm{mm}$ at $64 \mathrm{~h}$, indicating that the temperature difference decreased, the potential energy was small, and the cooling capacity transfer was slow. The values at the measuring points A5, A6, and A7 on the outside mirrored the measuring points A1 and A2. The difference was due to the existence of the original ground temperature and the better "cold" effect inside; this caused the temperature drop hysteresis of the measuring point A5 in the negative temperature zone and the measuring point $\mathrm{A} 2$, and its temperature is higher than A2. The results of the analysis of the spatial distribution of the common interface and the main surface were similar; the difference was that there was no freezing tube in the section where the common interface was located, and there were only a few internal frozen tubes with large spacing. Therefore, the temperature of the B4 measuring point in the first $16 \mathrm{~h}$ was lower than that of point B3. The "cold insulation" factor meant that the temperature of B3 was low and the main surface was the section where the inner row and the middle row were connected; the temperature difference was greater here due to the different cooling capacity. The temperature gradient between points $\mathrm{C} 3$ and $\mathrm{C} 4$ at $2 \mathrm{~h}$ and $5 \mathrm{~h}$ was $0.034^{\circ} \mathrm{C} / \mathrm{mm}$; at $8 \mathrm{~h}$, it was $0.063^{\circ} \mathrm{C} / \mathrm{mm}$; and in the later period, it was basically stable at $0.073^{\circ} \mathrm{C} / \mathrm{mm}$.

Figures $8(d)-8(f)$ show the temperature distribution of each temperature measuring point during the return temperature period for the three sections. As mentioned above, during the freezing and reheating phases, the calcareous clay underwent a phase change around $-3.8^{\circ} \mathrm{C}$, and the rate of the temperature decrease or reheating changed significantly. The three times of $128 \mathrm{~h}, 156 \mathrm{~h}$, and $240 \mathrm{~h}$ were phase transition slow temperature recovery periods, and the temperature measurement points on the three cross sections corresponded to the temperature difference at these three times. 

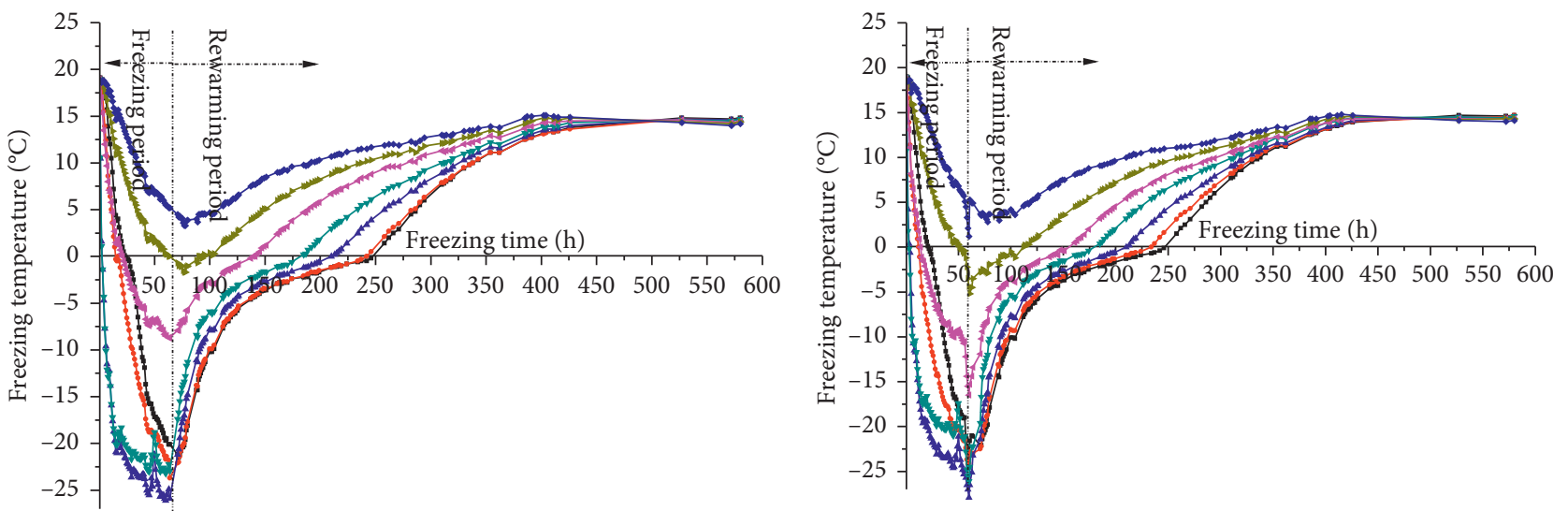

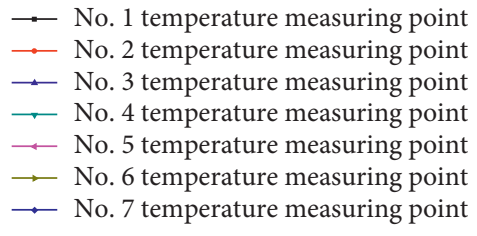

(a)

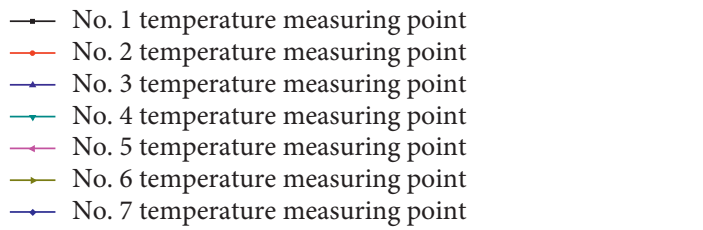

(b)

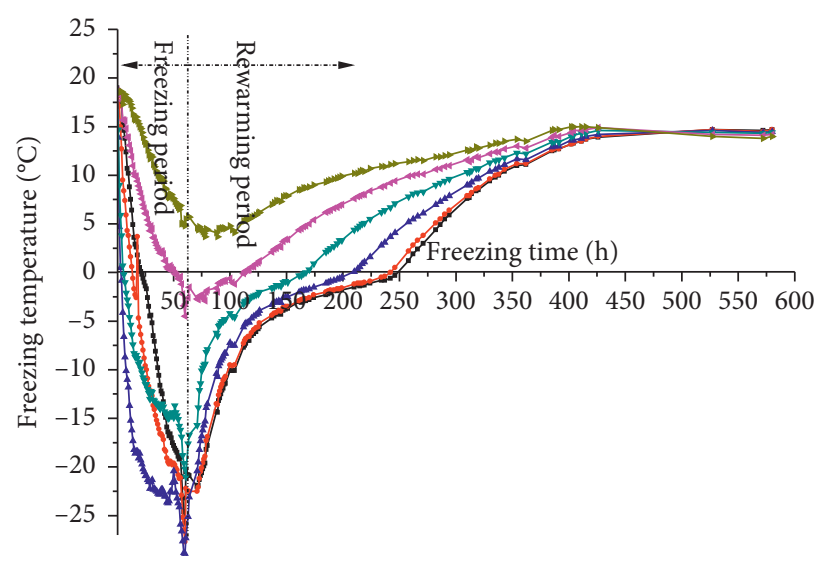

\begin{tabular}{l}
$\longrightarrow$ No. 1 temperature measuring point \\
$\square$ No. 2 temperature measuring point \\
$\square$ No. 3 temperature measuring point \\
$\square$ No. 4 temperature measuring point \\
$\rightarrow$ No. 5 temperature measuring point \\
$\longrightarrow$ Nomperature measuring point \\
\hline- temperature measuring point
\end{tabular}

(c)

FIgURE 7: The three interface temperatures for the freezing point against time. (a) Coprincipal (side A). (b) Common interface (side B). (c) The main interface (side C).

TABLE 4: The minimum temperature of each measuring point of the three sections and the rate of temperature drop in the active freezing period.

\begin{tabular}{|c|c|c|c|c|c|c|c|c|c|c|c|c|c|c|}
\hline \multirow{2}{*}{$\begin{array}{l}\text { Measuring point } \\
\text { Section }\end{array}$} & \multicolumn{2}{|c|}{1} & \multicolumn{2}{|c|}{2} & \multicolumn{2}{|c|}{3} & \multicolumn{2}{|c|}{4} & \multicolumn{2}{|c|}{5} & \multicolumn{2}{|c|}{6} & \multicolumn{2}{|c|}{7} \\
\hline & $\begin{array}{l}T_{\min } \\
\left({ }^{\circ} \mathrm{C}\right)\end{array}$ & $\begin{array}{c}\mathrm{V} \\
\left({ }^{\circ} \mathrm{C} / \mathrm{h}\right)\end{array}$ & $\begin{array}{l}T_{\min } \\
\left({ }^{\circ} \mathrm{C}\right)\end{array}$ & $\begin{array}{c}\mathrm{V} \\
\left({ }^{\circ} \mathrm{C} / \mathrm{h}\right)\end{array}$ & $\begin{array}{l}T_{\min } \\
\left({ }^{\circ} \mathrm{C}\right)\end{array}$ & $\begin{array}{c}\mathrm{V} \\
\left({ }^{\circ} \mathrm{C} / \mathrm{h}\right)\end{array}$ & $\begin{array}{l}T_{\min } \\
\left({ }^{\circ} \mathrm{C}\right)\end{array}$ & $\begin{array}{c}\mathrm{V} \\
\left({ }^{\circ} \mathrm{C} / \mathrm{h}\right)\end{array}$ & $\begin{array}{l}T_{\min } \\
\left({ }^{\circ} \mathrm{C}\right)\end{array}$ & $\begin{array}{c}\mathrm{V} \\
\left({ }^{\circ} \mathrm{C} / \mathrm{h}\right)\end{array}$ & $T_{\min }\left({ }^{\circ} \mathrm{C}\right)$ & $\mathrm{V}\left({ }^{\circ} \mathrm{C} / \mathrm{h}\right)$ & $T_{\min }\left({ }^{\circ} \mathrm{C}\right)$ & $\begin{array}{c}\mathrm{V} \\
\left({ }^{\circ} \mathrm{C} / \mathrm{h}\right)\end{array}$ \\
\hline Co-principal & -21.5 & 0.79 & -23.7 & 0.86 & -26.1 & 2.66 & -23.2 & 2.61 & -8.7 & 0.61 & -1.7 & 0.28 & 3.3 & 0.20 \\
\hline Common interface & -25.8 & 0.79 & -28.1 & 0.90 & -30.9 & 1.86 & -27.0 & 2.41 & -16.5 & 0.67 & -6.4 & 0.30 & 2.8 & 0.21 \\
\hline The main interface & -25.8 & 0.80 & -27.7 & 0.88 & -29.9 & 1.37 & -21.2 & 1.75 & -6.5 & 0.30 & 1.0 & 0.19 & - & - \\
\hline
\end{tabular}




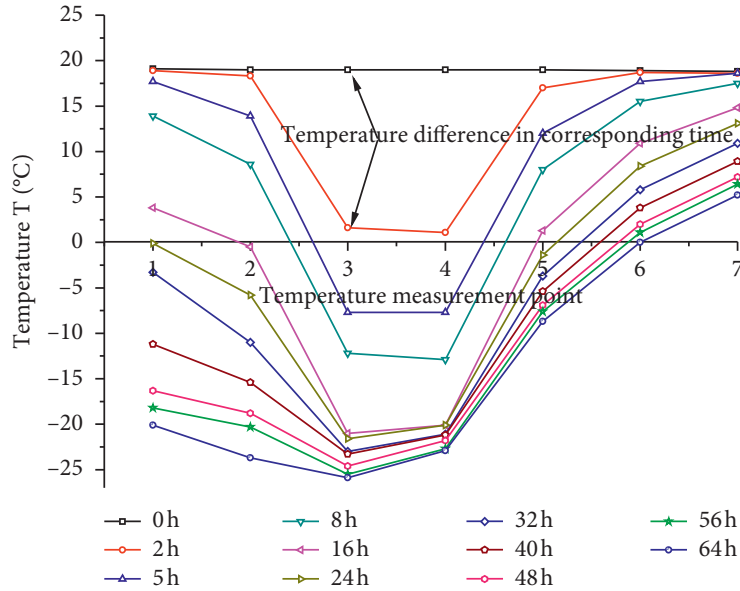

(a)

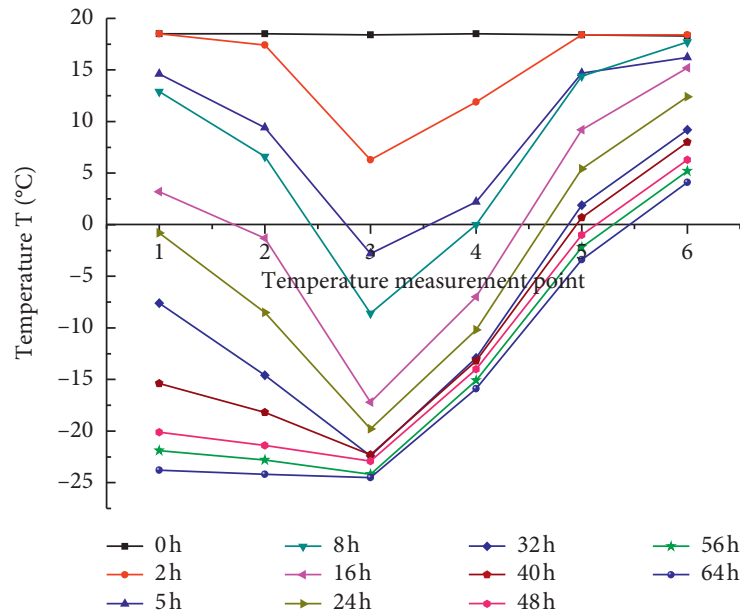

(c)

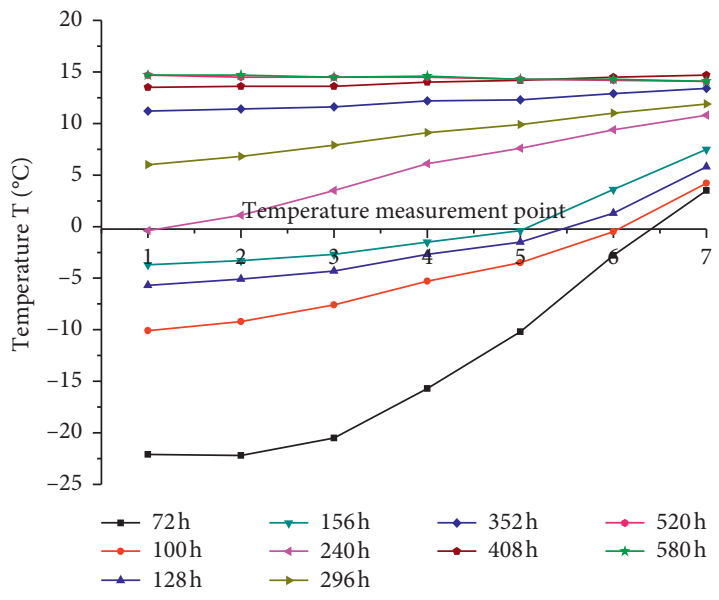

(e)

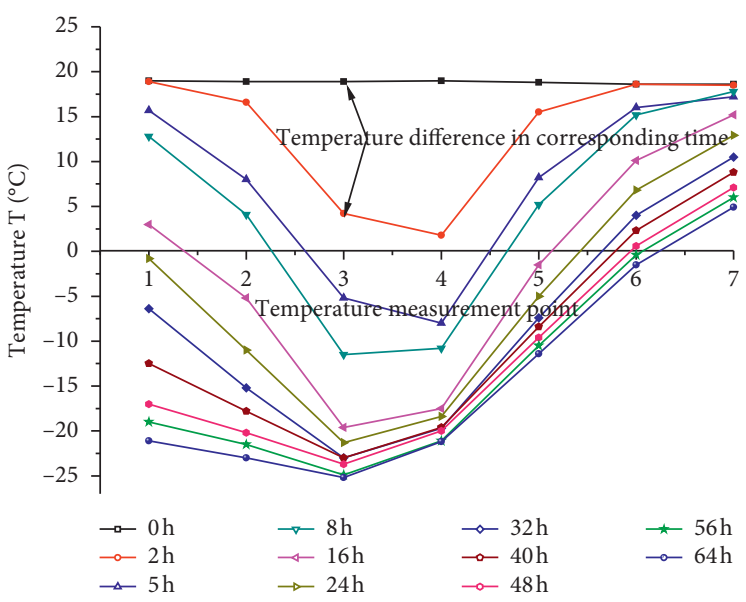

(b)

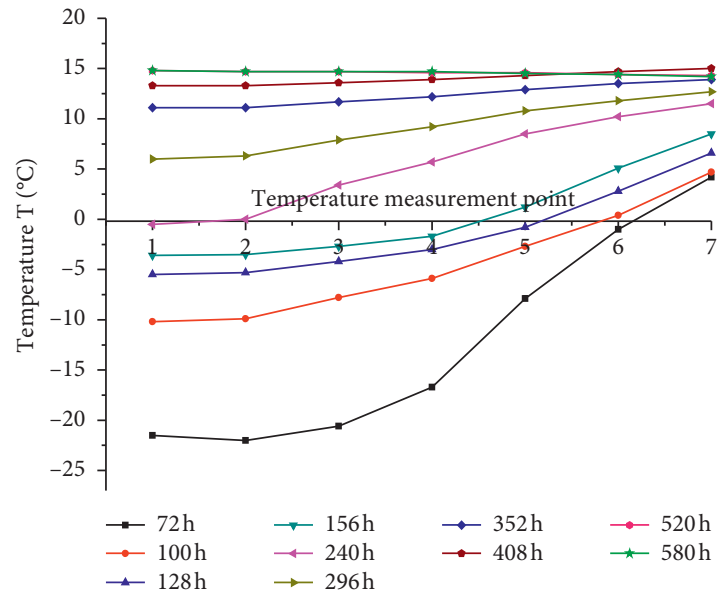

(d)

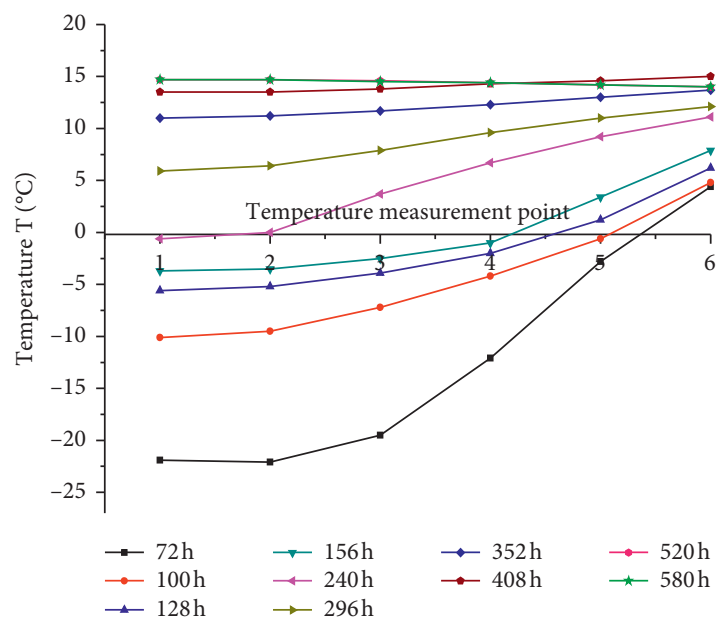

(f)

Figure 8: Temperature measurement and temperature cycle distribution map for the three interfaces. (a) Coprincipal. (b) Common interface. (c) The main interface. (d) Coprincipal temperature return. (e) Common interface temperature return. (f) Temperature return of the main interface. 
At measuring point 7 of each section (the main boundary surface No. 6), due to the natural melting of the frozen soil, the phase body needed to absorb a large amount of heat from the environment through the outer wall of the model. At the measuring point of section No. 7 (the main boundary surface No. 6), the soil was not frozen, but a large "relative" change in the temperature could also be seen between $156 \mathrm{~h}$ and $240 \mathrm{~h}$. Since the freezing point of calcareous clay is $-1.3^{\circ} \mathrm{C}$, but its supercooling temperature can be as low as $-3.8^{\circ} \mathrm{C}$, the temperature at points $2,3,4$, and 5 was higher than its supercooling temperature. This is the node where the frozen wall completely melted; the total duration of the wall melting process was $210 \mathrm{~h}$, and the freeze-thaw time ratio was $1: 1.91$.

4.3. The Overall Development Law of the Frozen Wall. By combining the test data of the three main test sections and the auxiliary test plane, based on the kriging difference method in the Surfer software, the freezing temperature field formed by the calcareous clay has been shown as an isotherm diagram, as shown in Figure 9. It should be noted that the measurement points of this test were divided into upper and lower planes, and each plane had three main sections in which the measurement points were arranged. The temperature field was constructed based on the temperature measurement points of the three main sections. The temperature could not be described completely due to the characteristics of the field distribution. The degree of compaction of the soil filling and the slight difference in the water content in all directions were ignored, and according to the layout characteristics of the frozen pipes as shown in Figure 4, a number of sections were selected at a certain angle from the semicircular plane and the corresponding measured section data were assigned to the plot. Among these, there were 2 main surfaces and 1 main boundary surface, and the total main surface was divided into $11.25^{\circ}$ sections, for a total of 16 sections. Figures 9(a)-9(f) show the contour maps of the temperature field at the corresponding moments in the test freezing section. It can be seen from the figure that the temperature of the entire fill area was basically the same at the beginning of the freezing process; that is, at $0 \mathrm{~h}$, there was a temperature difference of $0.5^{\circ} \mathrm{C}$. As the freezing progressed, the temperature rapidly decreased, and the temperature of the central area of the three rows of pipes dropped to $0^{\circ} \mathrm{C}$ around the $2 \mathrm{~h}$ mark, as shown in Figures 9(b) and 9(c); it can be seen that the $-1.3^{\circ} \mathrm{C}$ line started to intersect the position of the middle row of pipes at about $2.5 \mathrm{~h}$. It should be pointed out that according to the similarity theory, the flow rate of the refrigerant in the test was $C_{l}$, which was higher than the actual flow rate of the project, but the current test equipment could not achieve such a high flow rate; therefore in this test process, as much as possible, the refrigerant flow rate was guaranteed to freeze the tube and a constant temperature of $-32^{\circ} \mathrm{C}$ was maintained for cooling, reducing the test's errors. Although the test could not achieve a similar flow rate, according to the relationship between the heat flow similarity ratio, the refrigerant flow rate's similarity ratio, and the geometrical similarity ratio, it can be inferred from this that the intersection time of the $2.5 \mathrm{~h} 0^{\circ} \mathrm{C}$ line in the test was equivalent to the actual engineering freezing time of 127.6 days. It can be seen that due to the complex mineral composition and hydrophilicity of the calcareous clay, the soil layer has "difficult" freezing characteristics. In the $5 \mathrm{~h}$ freezing period, a freezing wall was formed in the "true" sense in the area of the three rows of freezing tubes. After $72 \mathrm{~h}$, the temperature in the freezing wall had been reduced to the minimum, and the freezing wall reached an average temperature of $-18^{\circ} \mathrm{C}$, and the freezing wall reached its design thickness. Because of the lack of understanding of the "difficult" freezing characteristics of calcareous clay, when the actual wellbore was excavated, the wellbore was unloaded, and the frozen wall of the layer where the calcareous clay was located had not reached its design strength; as a result, the pressure exerted by the surrounding soil on the frozen wall was nearly below the radial in situ stress of $5 \mathrm{MPa}$ (calcareous clay buried depth of $420 \mathrm{~m}$ ), and the frozen calcareous clay layer was prone to rheological deformation; as a result of this, a freezing pipe was sheared and destroyed.

Figures 9(g)-9(i) show the contour maps of the temperature field of the frozen calcareous clay during the recuperation period. It can be seen from the figure that the melting cycle of frozen calcareous clay is longer, which lasts $508 \mathrm{~h}$ to warm to room temperature, which is nearly 7 times of the freezing period. Figures $9(\mathrm{~g})$ and $9(\mathrm{~h})$ show the contour line cloud maps corresponding to $100 \mathrm{~h}$ and $192 \mathrm{~h}$ during the slow-phase recovery period. The temperature rise in the frozen soil area during this $92 \mathrm{~h}$ period did not exceed $9^{\circ} \mathrm{C}$; this has shown that the thermal conductivity of the calcareous clay was poor, the heat absorption from the outside was slow, and it had a long melting time.

The average temperature and thickness of the frozen wall could be calculated from the temperature measurement data, as shown in Figure 10. It can be seen from the figure that due to the difference in the temperature development of the three sections, the effective thickness of the frozen wall is formed on the main surface of the $5 \mathrm{~h}$ time boundary, and the frozen wall formed a circle at that time; the development trend of the frozen wall at the three interfaces was consistent. A faster time meant that the temperature dropped more quickly in the initial stage of freezing; it tended to be gentle in the later stage, and the thickness of the frozen wall changed slowly. The development speed of the thickness of the freezing wall is the fastest on the coprincipal (side A), the second is the main interface (side $\mathrm{C}$ ), and the common interface (side B) is the slowest. The development of the thickness of the frozen wall could be divided into two stages: the first stage was between 5 hours-16 hours; this period of time was the fastest stage of the development of the thickness of the frozen wall where the development speed was $17.9 \mathrm{~mm} / \mathrm{h}$. The second stage is from 16 hours to 70 hours, and the development speed of the thickness of the frozen wall is $1.96 \mathrm{~mm} / \mathrm{h}$. The average development speed of the thickness of the frozen wall was $5.4 \mathrm{~mm} / \mathrm{h}$; the actual development speed of the thickness of the frozen wall was $0.0123 \mathrm{~m} / \mathrm{d}$ in the early stage, and $0.0014 \mathrm{~m} / \mathrm{d}$ in the later stage, which was significantly less than the thickness of the frozen wall of the mine shaft and other 


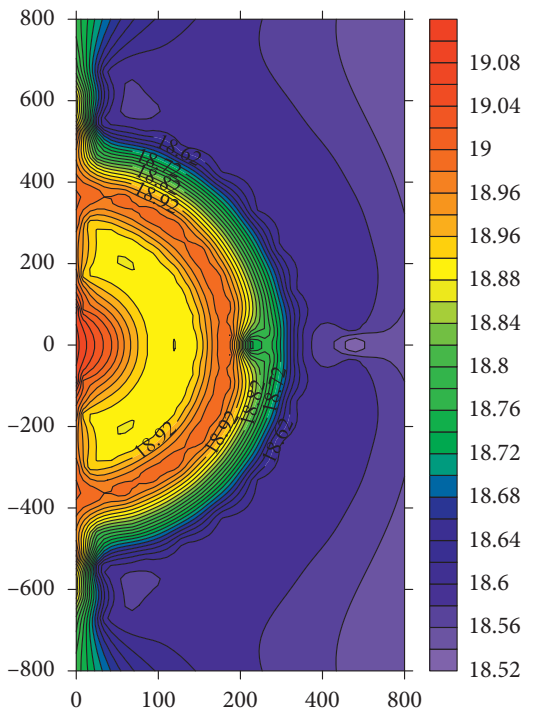

(a)

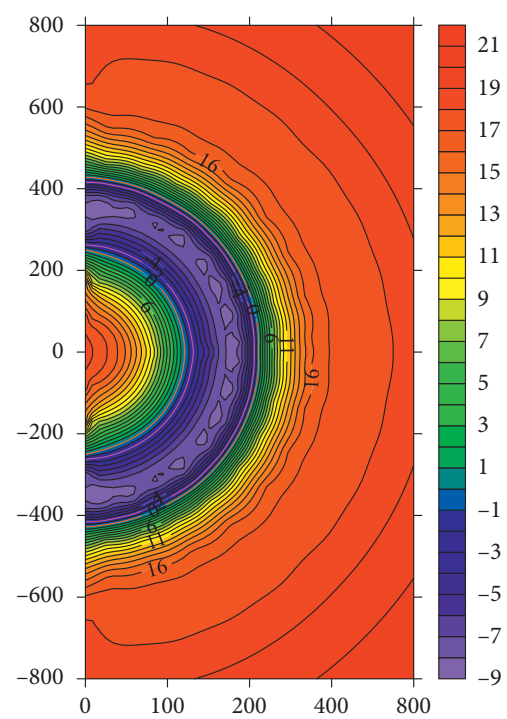

(d)

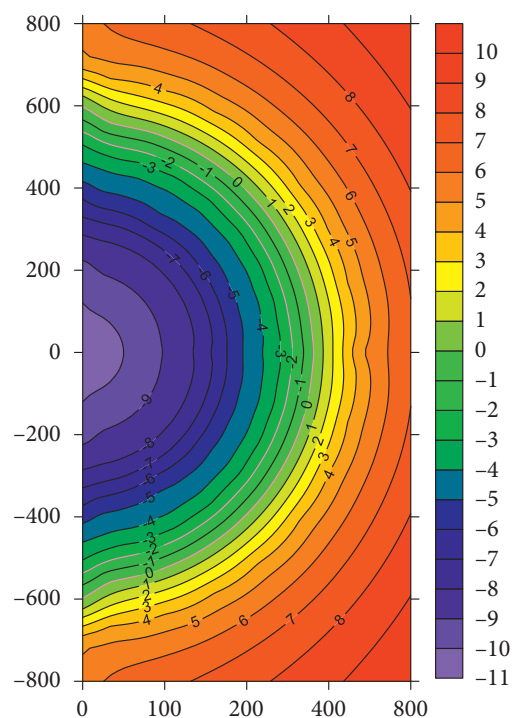

(g)

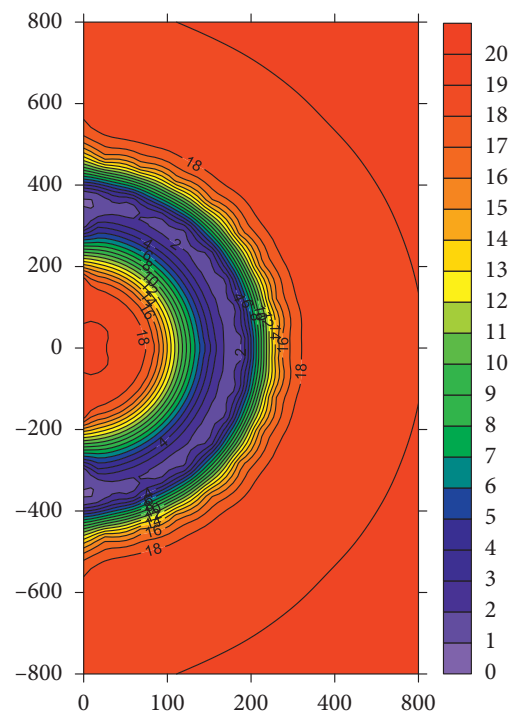

(b)

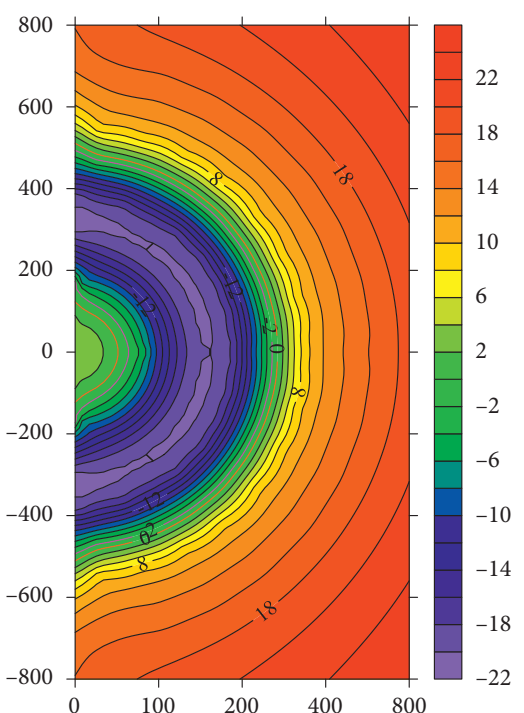

(e)

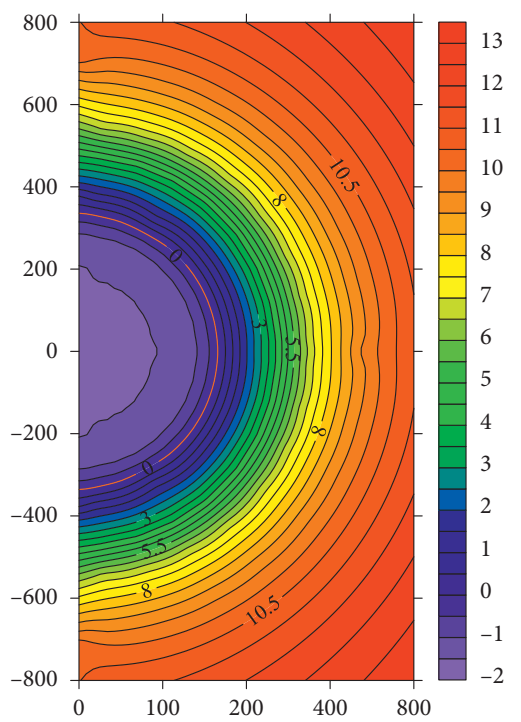

(h)

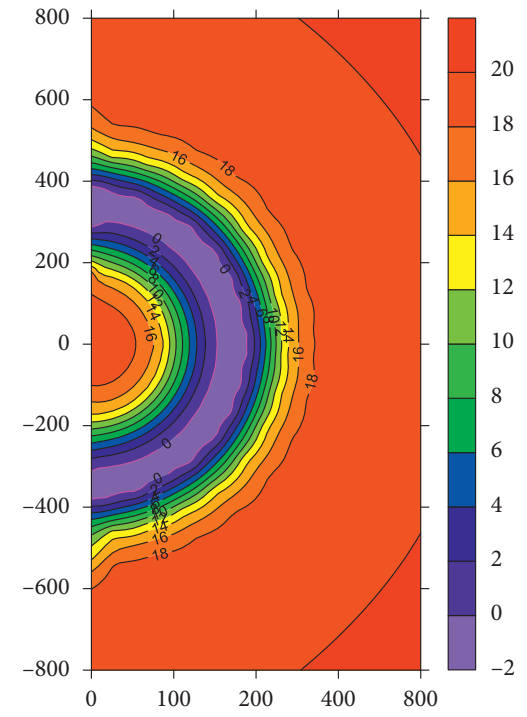

(c)

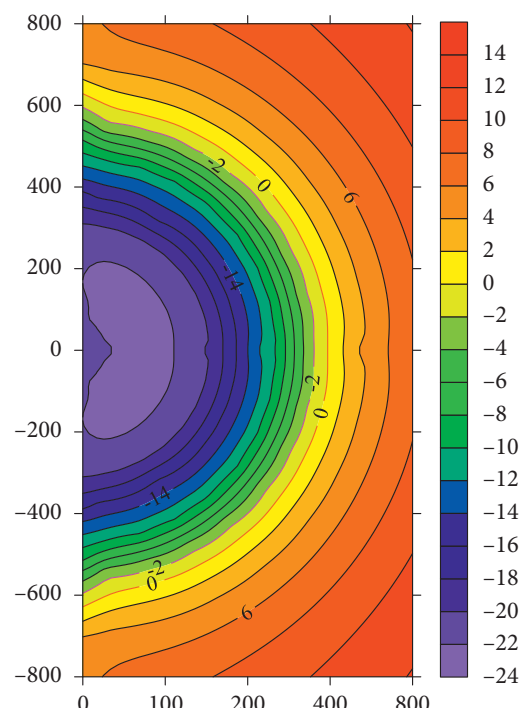

(f)

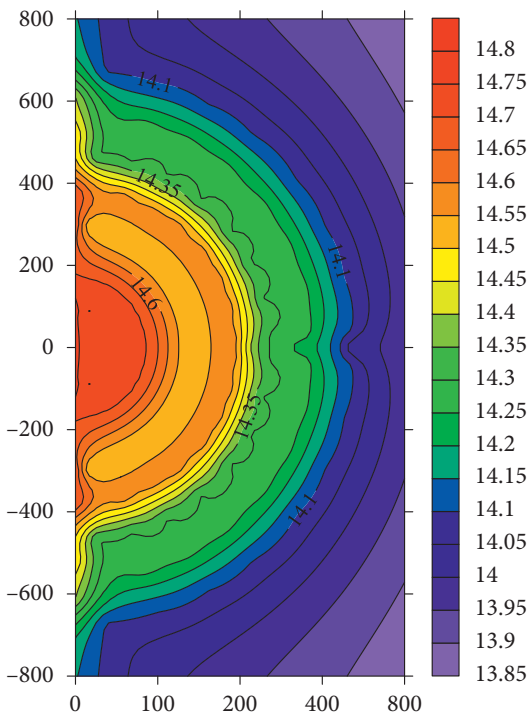

(i)

FIgURE 9: Cloud diagram of the freezing temperature field distribution of the three rows of pipes (small scale unit: ${ }^{\circ} \mathrm{C}$ ). (a) $0 \mathrm{~h}$. (b) $2 \mathrm{~h}$. (c) $3 \mathrm{~h}$. (d) 5 h. (e) 19 h. (f) 72 h. (g) 100 h. (h) 192 h. (i) 580 h. 


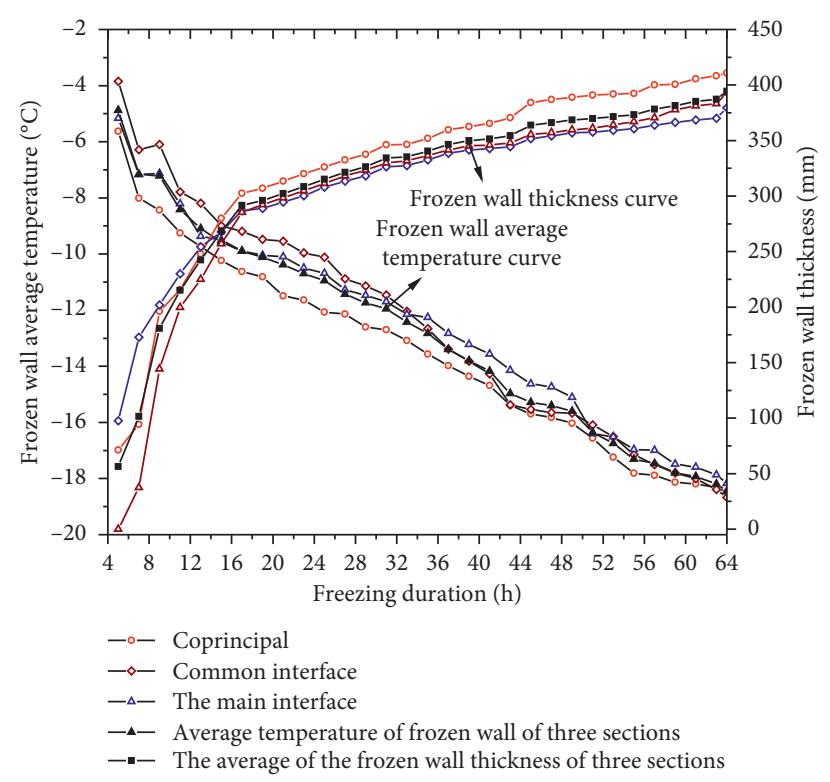

Figure 10: The relationship between the average temperature and the thickness of the frozen wall at the three interfaces and their average values with the freezing time.

mines in Zhangji's North District which was $0.0515 \mathrm{~m} / \mathrm{d}$ in the early stage and $0.02 \mathrm{~m} / \mathrm{d}$ in the later stage [29]. The complex chemical composition of calcareous clay (the high content of montmorillonite in calcareous clay has been preliminarily explored; this can account for more than $40 \%$ of the total minerals in the clay, along with illite. The total amount reaches about $90 \%$, see later research for details) and the hydrophilicity of the surface of the soil particles means they are attached to a thicker layer of bound water, coupled with frequent ion exchange and salt migration during the complex thermophysical and chemical interactions during freezing; this is the cause of the "difficult" freezing characteristics of calcareous clay. Therefore the frozen wall will develop slowly and the creep deformation is large; as a result, accidents such as breaks in the freezing pipes occur.

\section{Conclusion}

The "difficult" freezing characteristics of calcareous clay have caused many occurrences of pipe breakage during construction. In this paper, based on macromodel test research, an in-depth quantitative study on the temperature field expansion and development law of a freezing wall under the freezing conditions of calcareous clay has been carried out; from this, the following conclusions could be drawn:

(1) The complex mineral composition of calcareous clay, as well as ion exchange, dissolution, precipitation, and the other chemical reactions that occur in the water and soil system, means that the freezing point of calcareous clay is $-1.3^{\circ} \mathrm{C}$, its supercooling temperature can be as low as $-3.8^{\circ} \mathrm{C}$, and its thermal conductivity is low. Therefore, under the same cooling conditions, the layer of clay has poor thermal conductivity, and it freezes more slowly than the other layers of soil. The development speed of the frozen soil will then be slow, its strength will be low, and, as a result of this, the strength of the frozen wall will be uneven in the vertical direction, and it will be easy for shear to occur at the interface of an adjacent cracked soil layer.

(2) The initial intersection time $\left(-1.3^{\circ} \mathrm{C}\right)$ of the freezing temperature field in the experiment was $2.5 \mathrm{~h}$, which was equivalent to 87.5 days in the actual project; this is nearly 23 days longer than the designed intersection time of the clay layer for the freezing method of the mine's construction which was 65 days. In the current construction freezing method, the freezing time of the mine was nearly doubled to 45 days. A lack of understanding of the "difficult" freezing characteristics of the calcareous clay meant it was regarded as being the same as an ordinary clay layer. Excavation and unloading of a soil layer that has not completely formed an "effective" freezing wall that can resist high ground pressure can result in shear failure occurring in a freezing tube.

(3) For the three interfaces that were investigated in the experiment, the temperature of each temperature measurement point in the temperature field that was formed by the calcareous clay layer changed at the same time in an irregular saddle shape, and the time ratio between the formation of the frozen wall and complete melting was $1: 1.91$. The growth rate of the thickness of the frozen wall of the calcareous clay layer from 5 hours to 16 hours was $17.9 \mathrm{~mm} / \mathrm{h}$, and the growth rate from 16 hours to 70 hours was $1.96 \mathrm{~mm} / \mathrm{h}$; this corresponded to the actual development rate of the thickness of the frozen wall of $0.0123 \mathrm{~m} / \mathrm{d}$ and $0.0014 \mathrm{~m} / \mathrm{d}$, which was significantly smaller than the development speed of the freezing of the general sandy clay layer wall thickness of $0.0515 \mathrm{~m} / \mathrm{d}$ in the early stage and $0.02 \mathrm{~m} / \mathrm{d}$ in the later stage. This will cause the thickness of the freezing wall and its strength to be unevenly distributed in the vertical direction. This is the main cause of pipe fractures and therefore should be taken seriously in the construction of an actual project.

\section{Data Availability}

The data used to support the findings of this study are available from the corresponding author upon request.

\section{Conflicts of Interest}

The authors declare that they have no conflicts of interest.

\section{Acknowledgments}

This study was funded by the National Natural Science Foundation of China (51374010 and 51474004), the Natural Science Foundation of Anhui Province (2008085ME165), and the Key Academic Funding Project for Top-Notch Talents (gxbjZD2016045). 


\section{References}

[1] H. Ren, X. Hu, C. Jin, and J. Zhang, "Study on freezing effect and operation of profiled enhancing freezing-tube in freezesealing pipe roof," Tunnel Construction, vol. 35, no. 11, pp. 1169-1175, 2015.

[2] H. U. Xiangdong, L. I. Xinyi, and Y. Wu, "etc. Effect of waterproofing in Gongbei Tunnel by freeze-sealing pipe roof method with field temperature data," Chinese Journal of Geotechnical Engineering, vol. 41, no. 12, pp. 2207-2214, 2019.

[3] B. Zhang, W. Yang, and B. Wang, "Elastoplastic design theory for ultra-deep frozen wall considering large deformation features," Chinese Journal of Geotechnical Engineering, vol. 41, no. 7, pp. 1288-1295, 2019.

[4] W. Yang, D. U. Zibo, and Y. Zhijiang, "Plastic design theory of frozen soil wall based on interaction between frozen soil wall and surrounding rock," Chinese Journal of Geotechnical Engineering, vol. 35, no. 10, pp. 1857-1862, 2013.

[5] W. Yang and Y. Zhijiang, "Elastic-plastic design theory of frozen soil wall based on interaction between frozen wall and surrounding rock," Chinese Journal of Geotechnical Engineering, vol. 35, no. 1, pp. 175-180, 2013.

[6] H. U. Xiangdong and S. H. U. Chang, "Stress field analysis of functionally graded material frozen soil wall in double-rowpipe shaft freezing," Engineering Mechanics, vol. 31, no. 1, pp. 145-153, 2014.

[7] X. Hu, S. She, and R. Yu, "Average temperature calculation for straight single-row-piped frozen soil wall," Sciences in Cold and Arid Regions, vol. 3, no. 2, pp. 124-131, 2011.

[8] H. U. Xiangdong, F. Zhao, S. H. E. Siyuan, and S. H. U. Chang, "Equivalent parabolic arch method of average temperature calculation for straight double-row-pipe frozen soil wall," Journal of China Coal Society, vol. 37, no. 1, pp. 28-32, 2012.

[9] R. Chuanxin, B. Wang, and P. Shilong, "Study on mechanical characteristics of functionally graded material frozen soil wall basing on Druker-Prager strength criterion," Journal of Guangxi University, vol. 37, no. 40, p. 1344, 2015.

[10] B. Wang, R. Chuanxin, and H. Cheng, "Theoretical analysis of the double-row-pipe frozen soil wall basing on druker-prager strength criterion," Science Technology and Engineering, vol. 16 , no. 25 , pp. $44-50,2016$.

[11] J. Lin, H. Cheng, H.-B. Cai, B. Tang, and G.-Y. Cao, "Effect of seepage velocity on formation of shaft frozen wall in loose aquifer," Advances in Materials Science and Engineering, vol. 2018, pp. 1-11, 2018.

[12] H. B. Cai and R. Chuanxin, "Nonlinear analysis of freezing temperature field considering latent heat of phase change," Low Temperature Architecture Technology, vol. 37, no. 2, pp. 43-45, 2009.

[13] Z. He, R. Zu, K. Zhang et al., "Laboratory experiment of the influence of aeolian sand accumulation on permafrost temperature," Journal of Glaciology and Geocryology, vol. 37, no. 1, pp. 156-161, 2015.

[14] L. I. Haipeng, W. Yang, H. Jiahui, S. Lei, and T. Zhang, "Model test of frost heaving pressure during formation of clay freezing wall with two-cycle freezing-tube," Journal of Glaciology and Geocryology, vol. 33, no. 4, pp. 801-806, 2011.

[15] T. Wang and G. Zhou, "Analysis of temperature field around a single freeing pipe considering variability of soil parameters," Journal of China Society, vol. 39, no. 6, pp. 1063-1069, 2014.

[16] L. I. Jinhua, W. Yansen, L. I. Dahai, and C. Zhang, "Model tests on stress and deformation of freezing-pipes during multi-circle freezing before excavation," Chinese Journal of Geotechnical Engineering, vol. 33, no. 7, pp. 1072-1077, 2011.
[17] Y. U. Chuhou and P. Yang, "A discussion on the cause of freezing pipe breaking and the technology to auoid the breaking," Journal of Anhui University of Science and Technology (Natural Science), vol. 10, pp. 40-49, 1987.

[18] S. Zhang and L. I. Gongzhou, Special Well Drilling Technology for Deep Alluvium in Yongxia Mining Area, Coal Industry Press, Beijing, China, 2003.

[19] P. Yang, "Disposal of freezing pipe fracture and study of freezing temperature detection," Coal Technology of Northeast China, vol. 4, no. 4, pp. 8-10, 1996.

[20] M. Ma, H. Cheng, and R. Chuanxin, "Freezing construction technology for main shaft of Yangcun Coal Mine in deep and thick calcareous clay layer," Coal Engineering, vol. 49, no. 9, pp. 14-18, 2017.

[21] M. Ma, H. Cheng, and R. Chuanxin, "A numerical analysis of freezing pressure in frozen soils around a deep shaft based on the modified Nishihara model," Rock and Soil Mechanics, vol. 36, no. 10, pp. 3015-3022, 2015.

[22] Y. Liu, H. Liang, and T. Zhaohui, "Inverse modeling of geochemical behavior of $\mathrm{Ca}^{2+}$ in landslide water-soil interaction system near the Three Gorges Reservoir," Hydrogeologye Engineering Geology, vol. 39, no. 2, pp. 106-110, 2012.

[23] Y. Tan, B. Yu, X. Hu, and X. Liu, "Prediction model for thermal conductivity of unsaturated soil," Chinese Journal of Geotechnical Engineering, vol. 35, no. S1, pp. 129-133, 2013.

[24] J. Yang, Similarity Theory and Structural Model Test, Wuhan University of Technology Press, Wuhan, China, 2005.

[25] L. Tan, W. E. I. Changfu, T. Huihui, Z. Jiazuo, and W. Houzhen, "Experimental study of unfrozen water content of frozen soils by low-field nuclear magnetic resonance," Rock and Soil Mechanics, vol. 35, no. 6, pp. 53-59, 2015.

[26] E. J. A. Spanns and J. M. Baker, "The soil freezing characteristic: its measurement and similarity to the soil moisture characteristic," Soil Science Society of America Journal, vol. 60, no. 1, pp. 13-19, 1996.

[27] Y. A. N. Changgen, T. Wang, and H. Jia, "Influence of the unfrozen water content on the shear strength of unsaturated silt during freezing and thawing," Chinese Journal of Rock Mechanics and Engineering, vol. 38, no. 6, pp. 1252-1260, 2018.

[28] M. Ma, Y. Huang, and G. Cao, "Study on mechanical behavior of jurassic frozen sandstone in western China based on NMR porosity," Journal of Chemistry, vol. 38, 2020.

[29] K. Shen and R. Chuanxin, "Finite element analysis on freezing temperature field of Chagannaoer Mine auxiliary shaft," Joumal of Guangxi University, vol. 36, no. 4, pp. 647-652, 2011. 